\title{
SIGNIFICADO PROGNÓSTICO DAS MICROMETÁSTASES NOS LINFONODOS DO CARCINOMA COLORRETAL. DETECÇÃO IMUNOISTOQUÍMICA COM ANTICORPOS ANTICITOQUERATINA AE1/AE3
}

\author{
PROGNOSTIC SIGNIFICANCE OF MICROMETASTASES IN THE LYMPH NODES \\ OF COLORECTAL CARCINOMA. IMMUNOHISTOCHEMICAL DETECTION USING \\ AE1/AE3 ANTICYTOKERATIN ANTIBODIES
}

\author{
Rogério Tadeu Palma, TCBC-SP ${ }^{1}$ \\ Jaques Waisberg, TCBC-SP ${ }^{2}$ \\ Angélica Bráz Simões ${ }^{3}$ \\ Sansom Henrique Bromberg, ACBC-SP ${ }^{4}$ \\ FernandaAppolonio 5
}

\begin{abstract}
RESUMO: Objetivos: Identificar por imunoistoquímica eventuais micrometástases nos linfonodos regionais previamente considerados livres pelo exame histopatológico convencional e avaliar a influência do comprometimento destes linfonodos na sobrevivência dos doentes com carcinoma colorretal extirpado com intenção curativa. Método: Foram estudados 51 doentes portadores de carcinoma colorretal nos estádios A (13 casos) e B (38 casos), segundo a classificação de Dukes. Um total de 501 linfonodos previamente considerados livres pelo exame histopatológico convencional foi investigado por meio de técnica imunoistoquímica com anticorpos monoclonais anticitoqueratina AE1/AE3 para identificar células epiteliais. Cada bloco previamente fixado em formalina e embebido em parafina foi seccionado em três partes, obtendo-se de cada uma delas três cortes com espessura de 4 milimícron cada. Resultados: Em seis doentes (11,7\%) no estádio B de Dukes, células neoplásicas foram identificadas em sete linfonodos do mesocolo $(1,4 \%)$ previamente considerados livres de neoplasia pelo exame histopatológico convencional. Em um enfermo, a micrometástase era representada por aglomerado celular, enquanto que nos outros cinco doentes as micrometástases eram constituídas por células isoladas. A sobrevivência dos enfermos com micrometástases linfonodais foi menor do que a dos doentes com linfonodos não comprometidos, porém sem atingir diferença significativa. Conclusões: O método imunoistoquímico pode ser empregado com sucesso na detecção de células neoplásicas em linfonodos previamente considerados livres pelo exame histopatológico convencional. O acometimento dos linfonodos regionais por micrometástases não influenciou a sobrevivência dos doentes com carcinoma colorretal extirpado.
\end{abstract}

Descritores: Neoplasias do colo; Prognóstico; Linfonodos; Estadiamento de neoplasia; Imunoistoquímica.

\section{INTRODUÇÃO}

O carcinoma colorretal é uma das doenças malignas mais freqüentes no mundo ocidental e sua incidência está em eleva- ção ${ }^{1}$. Apesar do uso de diferentes procedimentos diagnósticos, no momento da cirurgia muitos doentes apresentam o tumor em estádio avançado e nos enfermos com lesões extirpáveis a sobrevivência de cinco anos atinge somente cerca de

1. Pós-graduado do Programa de Pós-Graduação em Gastroenterologia Cirúrgica do IAMSPE.

2. Encarregado do Setor de Diagnóstico e Terapêutica.

3. Patologista - Hospital Beneficente São Caetano (SP).

4. Coordenador do Programa de Pós-Graduação em Gastroenterologia Cirúrgica do IAMSPE.

5. Acadêmica - Faculdade de Medicina do ABC (SP).

Recebido em 25/06/2001

Aceito para publicação em 05/03/2002

Trabalho realizado nos Serviços de Gastroenterologia Cirúrgica e de Anatomia Patológica do Hospital do Servidor Público Estadual de São Paulo do Instituto de Assistência Médica do Servidor Público Estadual (HSPE-IAMSPE). 
$50 \%{ }^{2,3}$.

No carcinoma colorretal, as metástases linfonodais são importante fator prognóstico, pois a sobrevivência de cinco anos que pode atingir até 70 a $80 \%$ nos enfermos com neoplasias Dukes A ou B reduz-se para cerca de 30 a $40 \%$ naqueles portadores de tumores classificados no estádio $\mathrm{C}$ de Dukes ${ }^{2,4,5}$. A presença ou ausência de metástases linfonodais é de fundamental importância na acurácia do estadiamento de doentes com carcinoma colorretal, para assegurar que decisões a respeito de terapia adjuvante sejam adotadas corretamente.

Além disso, doentes com invasão tumoral transmural e com linfonodos não comprometidos pela neoplasia, estudados pelo método histopatológico convencional, apresentam sobrevivência variável e parte expressiva desses morre devido à recidiva tumoral local e/ou metástases a distância.

O impacto clínico da importância das micrometástases linfonodais no carcinoma colorretal foi avaliado em poucos estudos ${ }^{1,3,5}$ e ainda não foi obtido consenso a respeito do seu significado clínico. A maioria dos estudos confirma a existência de micrometástases, mas é contraditória a respeito do significado prognóstico de tais achados.

Os objetivos deste estudo foram identificar possíveis micrometástases de carcinoma, pela técnica imunoistoquímica com anticorpos monoclonais anticitoqueratina AE1/AE3, nos linfonodos do mesocolo previamente considerados, pela técnica convencional, livres de neoplasia, em doentes com carcinoma colorretal extirpado, classificados nos estádios A e B de Dukes e avaliar a influência das eventuais micrometástases linfonodais na sobrevivência desse grupo de doentes.

\section{MÉTODO}

Foram estudados 51 doentes portadores de carcinoma colorretal, no estádio A ou B, segundo a classificação de Dukes ${ }^{2}$, operados com intenção curativa no Serviço de Gastroenterologia Cirúrgica do Hospital do Servidor Público Estadual de São Paulo, no período de 1971 a 1982.

Os dados clínicos foram obtidos, retrospectivamente, da análise dos prontuários hospitalares dos doentes incluídos no estudo ou por entrevista ambulatorial com os doentes. Foram considerados critérios de inclusão a presença de carcinoma colorretal, confirmada pelo exame anatomopatológico, a extirpação operatória da lesão com intenção curativa e a classificação da neoplasia nos estádios A ou B da classificação de Dukes. O termo "curativo" implicou a ausência macroscópica de doença residual no final do procedimento cirúrgico. Nenhum dos enfermos foi submetido a tratamento neoadjuvante ou adjuvante. Doentes submetidos a cirurgias consideradas não curativas não foram incluídos nesta investigação.

Considerou-se como Dukes A as neoplasias que não atingiam a túnica muscular externa do segmento intestinal e sem acometimento linfonodal, e como Dukes B, as que se estendiam por toda a parede, atingindo inclusive o tecido adiposo adventício, porém com linfonodos livres.

Vinte e um doentes eram do sexo masculino $(41,2 \%)$ e 30 do feminino (58,8\%). A média de idade foi de 59,80 anos (31 a 86 anos). Todos os doentes eram brancos. Treze doentes foram classificados no estádio A de Dukes e outros 38 doentes no estádio B de Dukes. A média de idade dos doentes com tumores classificados no estádio A de Dukes foi de 62,85 anos e a dos enfermos com estádio B da classificação de Dukes foi de 58,74 anos, não havendo diferença significativa $(\mathrm{p}=0,311)$.

A neoplasia estava localizada no reto em 22 casos, no cólon sigmóide ou cólon descendente em 13 enfermos, no ceco ou cólon ascendente em outros 13 doentes e no cólon transverso em três casos. Em todos os enfermos, a avaliação pré-operatória e a inspeção intra-operatória não demonstraram doença metastática. $\mathrm{O}$ seguimento foi baseado em avaliações periódicas dos doentes, com procedimentos disponíveis na época do exame para cada caso. $\mathrm{O}$ seguimento ambulatorial foi de, no mínimo, cinco anos e consistiu, de modo geral, do exame clínico, retossigmoidoscopia e/ou colonoscopia, determinação do nível sérico do antígeno carcinoembriônico (CEA), ultra-sonografia abdominal, tomografia abdominal e pélvica e radiografia de tórax.

De cada peça cirúrgica foram obtidos um a 49 linfonodos (média de 9,8), os quais foram analisados após terem sido fixados em formalina e emblocados em parafina para exame histopatológico de rotina, corados pelo método da hematoxilina-eosina (HE) e considerados livres de células neoplásicas no exame histopatológico convencional. Para a realização do estudo imunoistoquímico, todos os linfonodos foram obtidos do arquivo histopatológico do Serviço de Anatomia Patológica. Um total de 501 linfonodos foi analisado: 271 linfonodos eram provenientes de carcinoma retal e 230 linfonodos de carcinoma cólico.

Cada bloco previamente fixado em formalina e embebido em parafina foi seccionado em três partes, obtendo-se, de cada uma delas, três cortes com espessura de 4 milimícron cada. Em seguida, os cortes foram deparafinizados em xileno, lavados repetidamente em etanol a $100 \%, 95 \%, 80 \%$ e $75 \%$ e reidratados em água destilada. Os cortes histológicos foram tripsinizados por 10 minutos com tripsina a $0,1 \%$ em água destilada com $\mathrm{pH}$ ajustado para 7,8 com hidróxido de sódio. As lâminas foram, então, lavadas em solução salina tamponada de fosfato (PBS), a atividade endógena da peroxidase foi inibida com $3 \%$ de peróxido de hidrogênio em metanol e novamente lavadas em PBS.

A preparação imunoistoquímica foi realizada utilizando a técnica da estreptavidina-biotina-peroxidase, como previamente descrita por Hsu et al. ${ }^{6}$. Seções de tecido foram incubadas com os anticorpos primários anticitoqueratina AE1/AE3 (Dako Corporation, Dinamarca). As seções de tecido foram, então, lavadas em PBS, incubadas com reagente secundário por 30 minutos e lavados novamente em PBS. As lâminas foram expostas ao reagente de ligação e submetidas à lavagem final com PBS. A reação da peroxidase foi realizada por meio da incubação das lâminas por dois a cinco minutos com 3,3 tetraidrocloreto-diaminobenzidina (DAB) (Sigma Corporation, EUA). As lâminas foram contracoradas com hematoxilina de 
Harris e montadas.

A observação microscópica foi realizada no microscópio ótico comum por patologista experiente com técnicas imunoistoquímicas. Considerou-se como micrometástase a presença de uma ou mais células epiteliais com coloração positiva para os anticorpos monoclonais anticitoqueratina AE1/AE3 nos linfonodos mesocólicos.

$\mathrm{Na}$ avaliação dos resultados optou-se pela utilização de testes estatísticos não paramétricos em função das amostras existentes. As variáveis quantitativas foram representadas por frequiência absoluta $(\mathrm{N})$ e relativa (porcentagem). Foram utilizados os modelos estatísticos da média aritmética, desvio padrão e teste da igualdade das médias ( $\mathrm{t}$ de Student). Em todos os testes fixou-se em $0,05 \%$ o nível para a rejeição da hipótese de nulidade (nível de significância de 95\%) de acordo com os padrões correntes em estudos biológicos, assinalando-se com asterisco (*) os valores significativos.

\section{RESULTADOS}

A técnica imunoistoquímica com utilização do coquetel de anticorpos monoclonais anticitoqueratina AE1/ AE3 detectou a presença de micrometástases em sete linfonodos $(1,4 \%)$ do total de 501 linfonodos previamente considerados livres de doença metastática do carcinoma colorretal pelo exame anatomopatológico convencional. Um único enfermo apresentou dois linfonodos comprometidos; outros cinco linfonodos comprometidos foram de outros cinco doentes, totalizando seis enfermos portadores de micrometástases $(11,7 \%)$, todos pertencentes ao estádio B de Dukes e representando 15,78\% deste grupo. Todas as células consideradas positivas para a expressão de citoqueratina tiveram sua morfologia estudada e sua natureza neoplásica epitelial confirmada.

Em relação à localização dos tumores, em 22 doentes com carcinomas retais foram examinados 230 linfonodos, encontrando-se micrometástases em um único linfonodo $(0,4 \%)$ de um enfermo $(4,5 \%)$ com neoplasia retal. Nos 29 enfermos com carcinoma cólico foram estudados 271 linfonodos e cinco doentes $(17,2 \%)$ apresentaram seis linfonodos $(2,2 \%)$ com micrometástases.

As micrometástases localizavam-se nos seios subcapsulares em quatro enfermos (57\%), observando-se micrometástases difusas no interior dos linfonodos em dois doentes $(28,5 \%)$ e micrometástase no seio paracortical em um caso $(14,5 \%)$. Em um enfermo a micrometástase era representada por aglomerado celular (Figura 1), enquanto nos outros cinco doentes a mesma era constituída de células isoladas (Figura 2), em dois casos as células neoplásicas encontravam-se localizadas difusamente no interior do linfonodo.

A média de sobrevivência dos doentes classificados como Dukes A foi de 105,54 meses, enquanto a dos doentes com estádio B de Dukes foi de 75,18 meses, havendo diferença significativa entre esses valores $(p=0,031)$ (Tabela 1).

A média de sobrevivência dos doentes portadores de carcinoma colorretal extirpado com estadiamento A ou B da classificação de Dukes sem presença de micrometástase linfonodal foi de 84,51 meses e nos enfermos com comprometimento linfonodal foi de 71 meses, não havendo diferença significativa ( $p=0,488)$ (Tabela 2$)$. Nos enfermos com ausência de comprometimento linfonodal, a média de sobrevivência foi de 75,97 meses, sem diferença significativa ( $\mathrm{p}=$ 0,804 ) (Tabela 3) com a dos enfermos com micrometástase. Três doentes com micrometástases linfonodais faleceram por recidiva locorregional ou a distância da neoplasia, com média do tempo livre da doença de 15,6 meses e média de sobrevivência de 29,3 meses. Já outros três doentes com micrometástase linfonodal sobreviveram mais de cinco anos após a operação. Dos 32 enfermos com estadiamento B de Dukes sem micrometástase linfonodal, sete faleceram por recidiva locorregional ou a distância da doença, com média de tempo livre de doença de 22,5 meses e média de sobrevivência de 25,8 meses.

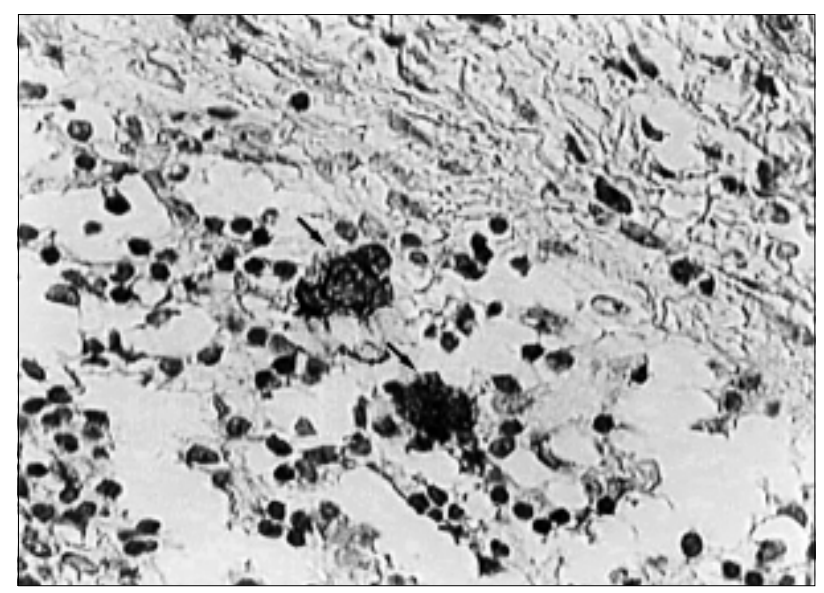

Figura 1 - Fotomicrografia de linfonodo corado pela técnica imunoistoquímica com anticorpos anticitoqueratina AE1/AE3, exibindo duas células neoplásicas isoladas (setas) nos seios subcapsulares (contracoloração com hematoxilina de Harris, $250 x)$.

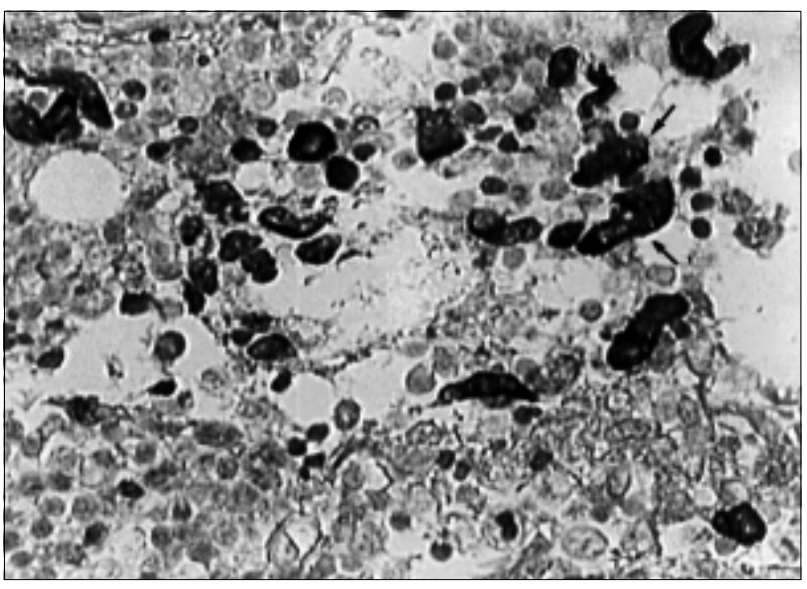

Figura 2 - Fotomicrografia de linfonodo corado pela técnica imunoistoquímica com anticorpos anticitoqueratina AE1/AE3, mostrando células neoplásicas agrupadas (setas) (contracoloração com hematoxilina de Harris, 250x). 
Tabela 1

Média de sobrevivência, em meses, dos doentes com carcinoma colorretal extirpado de acordo com a classificação de Dukes

\begin{tabular}{c|c|c|c}
\hline Classificação de Dukes & $N$ & Média de sobrevivência & D.P. \\
\hline A & 13 & 105,54 & 37,24 \\
B & 38 & 75,18 & 44,16
\end{tabular}

\begin{tabular}{lll}
\hline $\mathrm{t}$ de Student $=2,20$ & G.L. $=49$ & $\mathrm{p}=0,031^{*}$ \\
\hline
\end{tabular}

$N=$ número de doentes

D.P. $=$ desvio padrão

G.L. = graus de liberdade

$*$ = significativo

Tabela 2

Média de sobrevivência, em meses, dos doentes com carcinoma colorretal extirpado com estadiamento A ou B da classificação de Dukes, com micrometástase linfonodal presente ou ausente

\begin{tabular}{l|c|c|c}
\hline Micrometástase & $N$ & Média de sobrevivência & D.P. \\
\hline Presente & 6 & 71,0 & 48,85 \\
Ausente & 45 & 84,51 & 43,91 \\
\hline $\mathrm{t}$ de Student $=0,699$ & \multicolumn{2}{c|}{ G.L. $=49$} & $\mathrm{p}=0,488$ (N.S.) \\
\hline
\end{tabular}

$N=$ número de doentes

D.P. = desvio padrão

G.L. = graus de liberdade

N.S. = não significativo

Tabela 3

Sobrevivência média, em meses, dos doentes com carcinoma colorretal extirpado com estadiamento B da classificação de Dukes, com micrometástase linfonodal presente ou ausente

\begin{tabular}{lccc}
\hline Micrometástase & $N$ & Média de sobrevivência & D.P. \\
\hline Presente & 6 & 71,00 & 48,85 \\
Ausente & 32 & 75,97 & 44,03 \\
\hline $\mathrm{t}$ de Student $=0,25$ & & G.L. $=36$ & $\mathrm{p}=0,804$ (N.S.) \\
\hline
\end{tabular}

$N=$ número de doentes

D.P. = desvio padrão

G.L. = graus de liberdade

$N . S .=$ não significativo

\section{DISCUSSÃO}

"Nós ainda não nos demos conta suficientemente que a cirurgia da doença maligna não é a cirurgia de órgãos: é a anatomia do sistema linfático"

(Enker et al. $)^{7}$.

Nos portadores de neoplasias sólidas, a sobrevivência dos doentes não é determinada unicamente pela mera presença de células neoplásicas detectadas na drenagem linfática ou venosa da lesão primária ou na circulação ge- $\mathrm{ral}^{8-10}$, o que sugere a participação de fatores próprios do hospedeiro ou a interação entre estes e as células neoplásicas na produção do crescimento progressivo ${ }^{4,10,11} \mathrm{e}$ a necessidade de grandes quantidades de células ou conglomerados de células para alcançar a implantação metastática com sucesso ${ }^{12}$. Este evento poderia explicar, ao menos parcialmente, os resultados do presente estudo, onde a detecção das micrometástases linfonodais não representou impacto negativo na sobrevivência dos doentes.

Pode-se especular que, em indivíduos imunocompetentes, estas células isoladas não são suficientes para cons- 
tituir metástase e que seriam destruídas por mecanismos imunológicos ${ }^{13}$. Assim, é possível que a carga tumoral bioagressiva contida nas micrometástases seja de impacto baixo e o seu desenvolvimento contido pelas defesas imunológicas inespecíficas e/ou específicas do hospedeiro.

O preparado de citoqueratina AE1/AE3 é feito de dois anticorpos monoclonais que reagem com células de epitélio simples, ductal e escamoso ${ }^{14} \mathrm{e}$, portanto, com capacidade de reação com adenocarcinomas e com grande especificidade para carcinomas ${ }^{15,16}$.

Neste estudo, houve exeqüibilidade do método imunocitoquímico para identificação de micrometástases linfonodais de carcinoma colorretal utilizando anticorpos monoclonais anticitoqueratina AE1/AE3. A definição de especificidade do método foi a presença de células epiteliais citoqueratina positivas em linfonodos do mesocolo de doentes com carcinoma colorretal.

A diferença na escolha do anticorpo, procedimentos de coloração e de interpretação podem explicar, em parte, os resultados discrepantes encontrados na literatura.

Greenson et al. ${ }^{17}$ postularam que doentes com carcinoma colorretal com estadiamento B de Dukes e que faleceram pela moléstia, tinham doença oculta micrometástatica em seus linfonodos pericólicos no momento do diagnóstico inicial. Estes autores estudaram, retrospectivamente, 568 linfonodos de 50 enfermos (11,3 linfonodos por doente) utilizando coloração imunoistoquímica com coquetel de anticorpos anticitoqueratina AE1/AE3. A coloração foi positiva em 33 linfonodos de 14 enfermos; seis doentes $(43 \%)$ faleceram de carcinoma colorretal antes de 66 meses e somente um dos enfermos sem micrometástases (3\%) faleceu antes de 66 meses. No estudo citado, o prognóstico foi significativamente pior nos doentes com linfonodos com células citoqueratina positivas, indicando presença de micrometástases. Em função destes resultados, recomendaram a coloração para citoqueratina dos linfonodos pericólicos como método rotineiro em doentes com carcinoma colorretal com estádio B de Dukes. No presente estudo, tal correlação não foi possível de ser demonstrada, apesar do número de casos e de linfonodos dissecados serem semelhantes.

Jeffers et al. ${ }^{5}$ estudaram, em doentes com carcinoma colorretal estadiados como Dukes B, a detecção imunoistoquímica de micrometástases em linfonodos considerados não comprometidos. Foram examinados 559 linfonodos de 77 enfermos submetidos à coloração imunoistoquímica com anticorpos anticitoqueratina AE1/AE3. Foram detectadas micrometástases em 19 casos correspondendo a $25 \%$ dos doentes estudados. Observaram que em dez enfermos havia a presença de aglomerados de células neoplásicas e em nove outros havia apenas células tumorais isoladas. A presença das micrometástases não estava relacionada com a idade, sexo, localização do tumor, tamanho do tumor ou diferenciação neoplásica. Como a sobrevivência estimada de dez anos não foi diferente para os doentes com ou sem micrometástases linfonodais, concluíram que a presença de micrometástases linfonodais detectáveis apenas pela técnica imunoistoquímica nos doentes com carcinoma colorretal e estadiados como Dukes B não justificaria sua classificação em estádios mais avançados da doença. Nosso trabalho examinou número semelhante de linfonodos (501), porém foram incluídos casos de carcinoma colorretal classificados como Dukes A ou B e não somente Dukes B como fizeram os autores mencionados. Além disso, considerados apenas os portadores de lesões Dukes B, o índice de incidência de micrometástases obtido por estes autores (25\%) foi expressivamente maior do que a encontrada no presente estudo $(15,8 \%)$. Exceto em um de nossos casos, a micrometástase era representada por células neoplásicas dispostas difusamente no linfonodo $(16,6 \%)$, diferentemente dos dez casos $(52,6 \%)$ de conglomerados celulares observados por Jeffers et al..$^{5}$. No presente estudo, em concordância com o desses últimos autores, a sobrevivência não se associou à presença ou não de micrometástases linfonodais.

Nesta casuística, o índice de identificação de micrometástases em doentes operados de carcinoma colorretal com estádio B de Dukes foi menor $(15,8 \%)$ do que a do estudo de Adell et al. ${ }^{18}$ (39\%) que utilizou os subtipos de anticorpos anticitoqueratina 8,18 e 19, diferentes daqueles por nós utilizados. Apesar disto, tanto no estudo de Adell et al..$^{18}$ quanto na presente investigação, a presença de micrometástases linfonodais não causou impacto negativo na sobrevivência dos doentes. É possível que diferenças na expressão dos epítopos dos anticorpos utilizados ou mesmo no número e espessura de cortes realizados nos linfonodos possam ter contribuído para explicar a diferença no número de células citoqueratina positivas encontradas nos dois estudos.

O reestadiamento a partir da detecção do envolvimento micrometastático pode não ter implicações clínicas objetivas, uma vez que os resultados deste estudo, a exemplo dos de outros autores ${ }^{1,5,13,18-20}$, revelaram ausência de impacto negativo da presença de micrometástases na sobrevivência dos doentes submetidos à extirpação curativa do carcinoma colorretal. Por outro lado, outros investigadores sustentaram que a identificação de micrometástases linfonodais teria influência negativa na sobrevivência dos seus portadores ${ }^{3,17,21}$. De qualquer modo, observa-se que doentes com carcinoma colorretal com estádio B de Dukes representam grupo heterogêneo, onde $50 \%$ evoluem de maneira satisfatória, enquanto a outra metade destes enfermos exibe prognóstico semelhante ao dos doentes com estádio C de Dukes ${ }^{22}$. É possível que estes grupos possam ser distinguidos pela análise da presença de doença micrometastática nos linfonodos do mesocolo, o que determinaria o subestadiamento do tumor ${ }^{20}$.

No presente estudo, procuramos demonstrar que a técnica de imunoperoxidase com anticorpos monoclonais anticitoqueratina é capaz de identificar micrometástases em linfonodos pericólicos não observados na coloração de rotina com HE. Questão central é a definição da necessidade da realização rotineira de coloração imunoistoquímica com anticorpos anticitoqueratina para identificação de micrometástases nos linfonodos do mesocolo nos doentes portadores de carcinoma colorretal com estádio Dukes B e, em caso da constatação da presença de micrometástases linfonodais, se este grupo de enfermos beneficiar-se-ia da ministração de quimioterapia adjuvante ou outra modalidade de tratamento complementar. 
Os resultados do presente estudo permitiram concluir que foi possível a identificação, por meio de técnica imunoistoquímica utilizando anticorpos monoclonais anticitoqueratina AE1/AE3, de células neoplásicas em linfonodos do mesocolo previamente considerados livres de neoplasia pelo exame histopatológico convencional nos enfermos submetidos à extirpação considerada curativa do carcinoma colorretal com estadiamento A ou B de Dukes. Apesar de nenhum dos doentes com estadiamento A de Dukes apresentarem micrometástases linfonodais e da ausência de diferença significativa entre a sobrevivência dos doentes com ou sem micrometástase linfonodal, a constatação que três enfermos com micrometástases linfonodais faleceram por recidiva da doença neoplásica pode indicar a participação deste acometimento na evolução da doença.

A capacidade de detectar células epiteliais nos linfonodos, mesmo durante revisão morfológica, sugere que o método imunoistoquímico pode ser empregado com sucesso para detectar, precocemente, metástases linfonodais, permitindo melhor entendimento dos seus processos de instalação e desenvolvimento. A possibilidade de que as metástases linfonodais são indicadoras e não governadoras da sobrevivência do doente deve estimular a geração de estudos para confirmar sua validade e contribuir para o entendimento dos mecanismos da disseminação das células neoplásicas como manifestação da variabilidade do comportamento biológico das neoplasias malignas.

\begin{abstract}
Background: To identify possible micrometastases by immunohistochemistry, to verify their morphological characteristics in regional lymph nodes and to evaluate their influence on the survival of patients with colorectal carcinoma that had been extirpated in a curative intent. Method: A study was made of 51 patients with colorectal carcinoma in stages A (13 patients) and B (38 patients), according to Dukes classification. A total of 501 lymph nodes previously considered free by conventional histopathological examination were submitted to immunohistochemical study using the technique of AE1/AE3 anticytokeratin monoclonal antibodies for the detection of neoplastic epithelial cells in their interior. Three serial sections, with three slices per section, with 4 millimicron were prepared from each slice. Results: Neoplastic cells were identified in six patients (11.7\%) at stage B in the Dukes classification, in seven lymph nodes of the mesocolon (1.4\%) previously considered free of neoplasia by conventional histopathological examination. In one case, micrometastasis was represented by a cell agglomeration, while in the other five cases, it was made up of isolated cells. Survival of patients with extirpated colorectal cancer with lymph node metastases was less than for the group of patients with involved lymph nodes, although without presenting a significant difference. Conclusions: The immunohistochemical method may be employed for the detection of neoplastic cells in lymph nodes previously considered free by conventional histopathological examination. The presence of a micrometastasis in regional lymph nodes did not significantly influenced survival of patients who had colorectal carcinoma extirpated with curative intent.
\end{abstract}

Key Words: Colonic neoplasms; Prognosis; Lymph nodes; Neoplasm staging; Immunohistochemistry.

\title{
REFERÊNCIAS
}

1. Broll R, Schauer V, Schimmelpenning $\mathrm{H}$ et al. Prognostic relevance of occult tumor cells in lymph nodes of colorectal carcinomas. Dis Colon Rectum, 1997, 40: 1465-1471.

2. Dukes CE, Bussey HJR. The spread of rectal cancer and its effect on prognosis. Br J Cancer, 1958, 12: 309-320.

3. Liefers GJ, Jansen AC, Van De Velde CJH et al. - Micrometastases and survival in stage II colorectal cancer. N Engl J Med, 1998, 339: 223-228.

4. Bromberg SH. Fatores morfológicos prognósticos do adenocarcinoma colo-retal. Dissertação (Doutorado em Medicina) São Paulo. Escola Paulista de Medicina, 1992.

5. Jeffers MD, O'Dowd GM, Mulcahy H et al. The prognostic significance of immunohistochemically detected lymph node micrometastasis in colorectal carcinoma. J Pathol, 1994, 172: 183-187.
6. Hsu SM, Raine L, Fanger H. Use of avidin-biotin peroxidase complex $(\mathrm{ABC})$ in imunoperoxidase techniques. J Histochem Cytochem, 1981, 29: 577-580.

7. Enker WE, Laffer UT, Block GE. Enhanced survival of patients with colon and rectal cancer is based upon wide anatomic resection. Ann Surg, 1979, 190: 350-360.

8. Roberts SS, Hangesh JW, Mcgrath RG et al. Prognostic significance of cancer cells in the circulating blood. Am J Surg, 1967, 113: 757-762.

9. Griffiths JD, Mckenna JA, Rowbotham HD et al. Carcinoma of the colon and rectum: circulating malignant cells and five-year survival. Cancer, 1973, 31: 226-236.

10. Cady B. Lymph node metastasis: indicators, but not governors of survival. Arch Surg, 1984, 119: 1067-1072.

11. Fisher B, Fisher ER. Barrier functions of lymph node to tumor cells and erythrocytes. Cancer, 1967, 20: 19071913. 
12. Weiss L, Glaves D, Waite DA. The influence of host immunity on the arrest of circulating cancer cells, and its modification by neuraminidase. Int J Cancer, 1974, 13: 856-862.

13. Cutait R, Alves VAF, Lopes LC et al. Restaging of colorectal cancer based on the identification of lymph node micrometastases through immunoperoxidase staining of cea and cytokeratins. Dis Colon Rectum, 1991 34: 917-920.

14. Tseng SCG, Jarvinen MJ, Nelson WG et al. Correlation of specific keratins with different types of epithelial differentiation: monoclonal antibody studies. Cell, 1982, 30: 361-372.

15. Gown AM, Vogel AM. Monoclonal antibodies to human intermediate filament proteins. Distribution of filament proteins in normal human tissues. Am J Pathol, 1984, 114: 309-321.

16. Gown AM, Vogel AM. Monoclonal antibodies to human intermediate filaments proteins. Analysis of tumors. Am J Pathol, 1985, 84: 413-424.

17. Greenson JK, Isenhart CE, Rice R et al. Identification of occult micrometastases in pericolic lymph nodes of Dukes' B colorectal cancer patients using monoclonal antibodies against cytokeratin and CC49. Cancer, 1994, 73: 563-569.

18. Adell G, Boeryd B, Franlund B et al. Occurrence and prognostic importance of micrometastases in regional lymph node in Dukes' B colorectal carcinoma: an immunohistochemical study. Eur J Surg, 1996, 162: 637-642.

19. Davidson BR, Sams VR, Styles J et al. Detection of occult nodal metastases in patients with colorectal carcinoma. Cancer, 1990, 65: 967-970.

20. Oberg A, Stenling R, Tavelin B et al. Are lymph node micrometastases of any clinical significance in Dukes stages A and B colorectal cancer? Dis Colon Rectum, 1998, 41: 1244-1249.

21. Trojani M, Mascarel I, Bonichon F et al. Micrometastases to axilary lymph nodes from carcinoma of breast: detection by immunohistochemistry and prognostic significance. Br J Cancer, 1987, 55: 303-306.

22. Jass JR, Atkin WS, Cuzick J et al. The grading of rectal cancer: historical perspectives and a multivariate analysis of 447 cases. Histopathology, 1986, 10: 437 449.

Endereço para correspondência:

Dr. Jaques Waisberg

Rua das Figueiras, 550/134 — Bairro Jardim

09080-300 - Santo André-SP

E-mail: jaqueswaisberg@uol.com.br 